as a salvage procedure after failed portal vein embolization and portal vein ligation respectively.

Results Median increase of FLR volume was 139.25\% (range 40.00\%-157.78\%). Median hospital stay was 28.5 days (range 23-36). Histology report revealed two complete (R0) and two incomplete (R1) resections. Background liver histology revealed steatosis on two occasions and fibrosis on another. 90 day mortality was zero. Two patients developed grade II complications as per Clavien-Dindo classification, one grade IIIa and one IIIb. One patient is disease free after 36 months,. One patient died two years later from viral infection, and two had recurrence in liver and lymph nodes and were treated with microwave ablation and lymphadenectomy respectively.

Conclusions ALPPS procedure allows performing major liver resections for high volume neuroendocrine metastases while minimising the risk of post-operative liver failure.

\section{PTH-102 CIRRHOTIC PATIENTS WITH VITAMIN D DEFICIENCY FAIL TO RESPOND TO ORAL REPLACEMENT THERAPY}

Freya Rhodes*, Olivia Greenham, Emma Hunt, Tina Shah, David Patch, Jennifer Ryan, Rachel Westbrook. Royal Free London NHS Foundation Trust, London, UK

\subsection{6/gutjnl-2018-BSGAbstracts.258}

Introduction Vitamin D deficiency and reduced BMD are highly prevalent in patients with advanced chronic liver disease. For bisphosphonate treatment for osteoporosis to be effective vitamin D levels must be replete. Moreover, vitamin $\mathrm{D}$ deficiency has been associated with an increased risk of infections and increased rejection rates following liver transplantation. The optimal dose and route of vitamin D replacement in cirrhosis is unknown. BSG guidance currently recommends $800 \mathrm{IU} /$ day orally for all patients with cirrhosis/ cholestatic liver disease.

Methods Retrospective review of 218 cirrhotic patients undergoing evaluation for liver transplant between 2016 and 2017. Vitamin D 'severe deficiency' was defined as $<25 \mathrm{ng} / \mathrm{ml}$, 'deficiency' $25-50 \mathrm{ng} / \mathrm{ml}$ and normal $>50 \mathrm{ng} / \mathrm{ml}$. Response to oral vitamin D therapy was recorded.

Results Out of 218 patients, 128/218 (59\%) had low Vitamin D levels with 25\% $(\mathrm{n}=55) \quad$ 'severely deficient' and $33 \%$ $(\mathrm{n}=73)$ 'deficient'. Overall 33 patients with levels $<50 \mathrm{ng} / \mathrm{ml}$ $(52 \%)$, and 31 patients $(48 \%)$ with levels $>50 \mathrm{ng} / \mathrm{ml}$ received replacement therapy. $(p=0.86)$

Median daily dose of Vitamin D replacement was 2800 units/day (IQR 800-2800) in $<25 \mathrm{ng} / \mathrm{ml}$ group, 2860 units/ day (IQR 800-2800) in $<50 \mathrm{ng} / \mathrm{ml}$ group and 800 units/day (IQR 800-2000) in $>50 \mathrm{ng} / \mathrm{dl}$ group. No significant difference in dosing between these groups $(p=0.12)$.

Data on vitamin D levels pre and post 3 months of treatment with Vitamin D therapy were available in 58 patients. Patients received either 400IU/day $(n=6), 800-1600 \mathrm{IU} /$ day $(n=28)$ or $>1600 \mathrm{IU} /$ Day $(n=24)$. Median delta change in vitamins $D$ levels in the 3 groups were $-3 \mathrm{ng} / \mathrm{ml},-1 \mathrm{ng} / \mathrm{ml}$ and $12 \mathrm{ng} / \mathrm{ml}$ over the 3 month treatment period. An average daily dose of $>1600 \mathrm{IU} /$ day Resulted in a significantly greater increase in Vitamin D levels when compared to doses $<1600$ IU/day $(p=0.01)$, albeit still sub optimal with only a median increase of $12 \mathrm{ng} / \mathrm{ml}$.

When those patients with Vitamin D levels of $<50 \mathrm{ng} / \mathrm{ml}$ were reviewed in isolation $(n=29), 82 \%$ failed to augment vitamin $\mathrm{D}$ levels to within the normal range $>50 \mathrm{ng} / \mathrm{dl}$ and no significant difference was found between dosages of vitamin D administered.

Conclusion Vitamin D deficiency is prevalent, affecting over $50 \%$ of patients with advanced cirrhosis. Oral vitamin D replacement therapy is ineffective in cirrhotics at repleting stores over a 3 month period irrespective of dose given.

Future evaluation of efficacy of IM administration in this unique cohort of patients is urgently needed to evaluate if this allows normalisation of Vitamin D levels.

\section{PTH-103 EPIDEMIOLOGY OF VITAMIN D DEFICIENCY AND BONE MINERAL DENSITY IN PATIENTS WITH CHRONIC LIVER DISEASE}

Freya Rhodes*, Olivia Greenham, Emma Hunt, Orla Kearney, David Patch, Jennifer Ryan, Rachel Westbrook. Royal Free NHS Foundation Trust, London, UK

\subsection{6/gutjnl-2018-BSGAbstracts.259}

Introduction Patients with chronic liver disease have increased risk of bone disease (BD) with reported prevalence of osteoporosis (OP) between $12 \%-55 \%$ and a high prevalence of Vitamin D deficiency. The aetiology is poorly understood with a complex interplay between endocrine, metabolic, nutritional and physical abnormalities. We aim to evaluate the influence of epidemiological parameters on bone mineral density and vitamin D levels in cirrhotics.

Methods Retrospective study of cirrhotic patients from 20162017. Data were collected on aetiology of cirrhosis, severity (UKELD/MELD score), bone mineral density (BMD), vitamin $\mathrm{D}$, body mass index (BMI) and hand grip strength. OP was defined as per WHO classification and Vitamin D deficiency as a Vitamin D level $<50 \mathrm{nmol} / \mathrm{L}$ with severe deficiency $<25 \mathrm{nmol} / \mathrm{L}$.

Results 248 patients were included, 180 male, 58 female, median age 57 years (IQR 49-63) and median BMI of 27. Underlying aetiology was ALD $(n=78)$, Viral $(n=56), \mathrm{PBC} /$ PSC $(n=46)$, NAFLD $(n=23)$ and AIH $(n=18)$. Median UKELD and MELD scores overall were 53 (IQR 49-57) and 14 (IQR 10-19). At the time of evaluation 141 (56.8\%) patients were either osteoporotic $(n=52)$ or osteopenic $(\mathrm{n}=99)$. The prevalence of BD was significantly higher in cholestatic diseases $(71.7 \%$, mean $\mathrm{T}$ score $-1.86+1.22)$ and lower in NAFLD (37\%, mean T score $-0.45+/-1.50)$ when compared to other aetiologies (ANOVA $p=0.0005) .120$ $(55.4 \%)$ patients were vitamin D deficient with 51 (25\%) patients having severe deficiency. Mean vitamin D level was highest in cholestatic disease $(75.5 \mathrm{ng} / \mathrm{ml}+/ 59.6)$ when compared to other aetiologies (ANOVA $\mathrm{p}=0.003$ ).

Liver severity scores (UKELD/MELD respectively) did not correlate with the presence of $B D(p=0.32 / p=0.53)$ but patients with higher MELD scores had lower vitamin D levels $(p=0.04)$. Reduced BMI correlated with the presence of BD $(\mathrm{p}<0.01)$ but not vitamin D level. Increased Hand Grip Strength (HGS) was associated with higher vitamin D levels $(p=0.049)$ and higher lumbar $T$ scores $(p=0.014)$. Vitamin D levels did not correlate with BMD $(p=0.77)$.

Conclusion Bone disease and vitamin D deficiency are prevalent in patients with cirrhosis, with cholestatic aetiologies having the highest prevalence of OP and NAFLD the lowest. 